\title{
Entrevista a Jürgen Golte: la iconografía prehispánica desde el universo Moche
}

\author{
Pedro Jacinto Pazos \\ jacintopazos@hotmail.com \\ Departamento Académico de Antropología \\ UNMSM
}

\begin{abstract}
Resumen
Si bien en las imágenes aparecen las divinidades, hay que ver que ya los señores se representan frente a la sociedad como descendientes de la divinidad " $x$ ”, $o$ descendiente de la divinidad " $y$ "; de esta forma se legitima el poder con una idea sobre un pasado primordial donde se construye la diferenciación social y la división del trabajo y, por esto es que hay un énfasis sobre ese orden primordial porque justifica la diferenciación del presente y el rol que tienen los diversos subgrupos de la sociedad en la perpetuación del orden. Es una idea que los moches deben haber tenido de manera muy extraordinaria y que por las interrelaciones entre los diversos grupos sociales, tenían que coordinar para que se produzca bien el futuro. El sentido de los ritos moches, como se puede ver, es organizar la producción del futuro a través de la interacción social.
\end{abstract}

Palabras clave: Iconografía moche, tinkuy, cosmovisión andina, cultura peruana.

\begin{abstract}
While divinities appear in the images, the lords already represent themselves to society as descendents of divinity " $x$ " or divinity " $y$ ", then power is legitimated in such way after the idea of a paramount past, where social differentiation and work division is configured. That is why this paramount order is remarked, and also because it justifies the current differentiation and the role that diverse society subgroups have in the perpetuation of order. Is basically an idea that moche people must have had as an extraordinary way of thinking, and since they had to interrelate with diverse social groups, coordination was imperative in order to rightfully produce the future. Yet, the sense of moche rites is to organize the production of the future through social interaction.
\end{abstract}

Key words: Moche iconography, tinkuy, cosmovision Andean, Peruvian culture. 


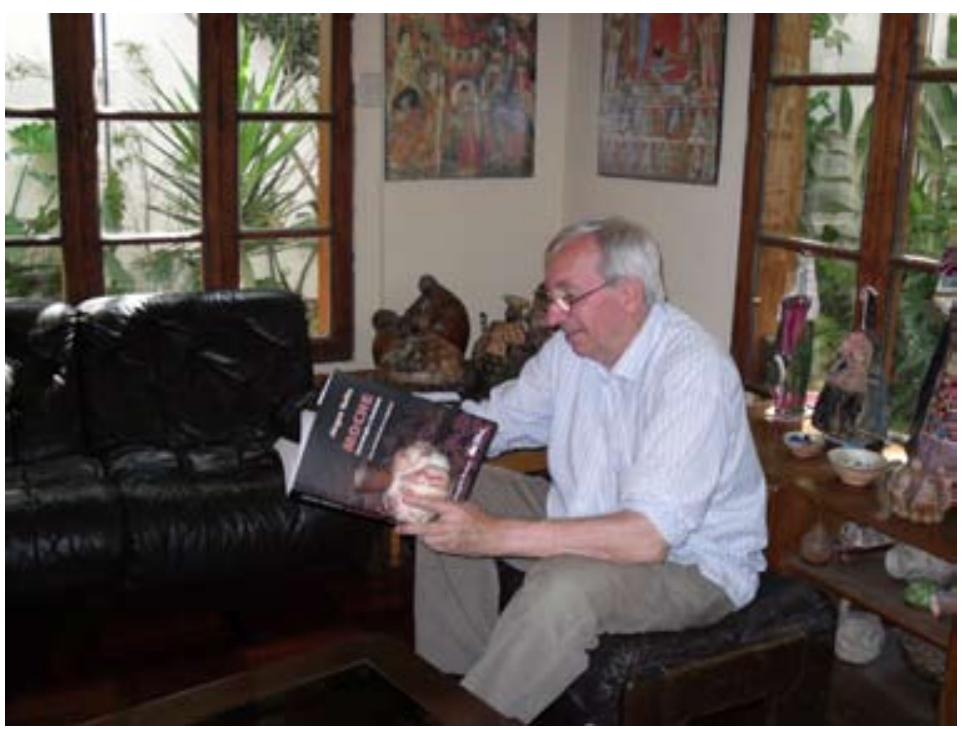

Jürgen Golte, releyendo su última publicación sobre el universo cultural mochica.

Pedro Jacinto Pazos. Nuestra preocupación, esta vez, es en función al libro que ha publicado últimamente sobre la Iconografía Moche ${ }^{1}$, le pregunto directamente, ¿por qué la cultura moche y por qué no otro tipo de culturas peruanas, conocemos de sus publicaciones sobre la iconografía Nazca que parece tener en stand by, y sus trabajos sobre los dioses de Sipán, también moche, escrito hace buen tiempo, pero en realidad, por qué esa persistencia sobre la cultura moche? ${ }^{2}$

Jürgen Golte. Por una cuestión de predilección personal, es que la cultura moche me parece excepcionalmente impresionante en cuanto a estética, acabado, finura de los trabajos, y una preocupación mayor que tengo en todo esto que he hecho sobre moche, es para que los peruanos aprendan a relacionarse de otra manera con su pasado, y moche es una cultura del pasado con la cual primero la población peruana, se puede identificar muy visiblemente, que se puede valorar fácilmente y que además es mundialmente reconocida como una de las grandes culturas excepcionales en el mundo. Entonces, como que en moche se conjugan una serie de factores, que la hacen un objeto muy bueno para que los peruanos adopten una percepción diferente del pasado, de la que les ha quedado de la colonia y estas dos últimas centurias de la república.

Existe un poquito de intención hoy, que pienso, que una población que no valora su historia, no es consciente de la capacidad de creación de su pasado y, probablemente va a ser un poco creativa en el futuro y los moches demuestran de una manera excepcional que los peruanos antiguos han sido creadores de primera línea. Tanto en lo estético como en lo sistemático y filosófico son muy originarios. Y allí hay un causal para lo de moche. Y, en lo que respecta a otras culturas por ejemplo Wari, Tiahuanaco, o Nasca y Paracas, de hecho he trabajado también sobre Nazca, incluso he publicado un trabajo sobre iconografía Nazca y tengo en mi computadora unas doscientas páginas sobre

1 El libro aludido se presentó en el IEP el 14 de abril de 2009. El título es: Moche. Cosmología y sociedad. Una interpretación iconográfica. Lima, IEP/ CBC. 2009.

2 La entrevista fue realizada el 18 de abril de 2009. 
Tiahuanaco que probablemente voy a trabajar más. Aquí analizaré los relieves en las estelas de piedra, pero en los últimos años han aparecido una serie de tejidos Tiahuanaco a todo color, enteros, que muestran el mismo orden que ya se puede analizar en las estelas y, por lo tanto, es mucho más rico hacer una combinación entre el análisis de las estelas, los tejidos y otros objetos Tiahuanaco, cuyo sentido tiene otra razón que moche, que es una cultura de la cual hay una historia de la investigación muy larga, en más de cien años. Sé que hay gente académica que está pensando sobre esto, que después de todo es importante, Nazca, también en cierto grado se está trabajando desde los años veinte del siglo XX y Tiahuanaco en cierto grado también. Ya Uhle se fue a Tiahuanaco, y elaboró un plano. Después Polanski, a principios del siglo XX, trabajó mucho pero, en cuanto a la cerámica de Tiahuanaco, no hay un trabajo tan sistemático como el caso de moche y en cierto grado también en cuanto a las imágenes de Paracas gracias a Tello. Y de Nazca, es un poquito gracias a Eduard Seler, que escribió un trabajo en 1923 sobre Nazca que hasta el momento es la fuente de todos los que ahora se dicen especialistas de Nazca. Todos recurren a las ilustraciones de Seler que es profusamente ilustrado, con unas cuatrocientas imágenes, y hoy en día parece que los analistas son un poquito flojos, en cuanto a la reproducción de las imágenes, y Nazca es un poco difícil porque es de muchos colores, entonces no hay mucho trabajo por este lado. Y menos aún, si se abre esa nueva perspectiva, que he desarrollado para moche, del que en realidad, la exposición de sentido, la construcción de sentido en los huacos, es en un esquema tridimensional. Si eso se incluye a lo de Nazca, es un trabajo muy grande porque he visto que lo mismo que digo sobre moche, que existe un error eurocéntrico, que lo veo en los análisis anteriores de la iconografía moche, vale para Nazca; es decir, también en Nazca hay una exposición tridimensional de imágenes y construcción de sentido tridimensional.

PJP: ¿Este privilegio, por moche, es preocupado en ver una contraposición con respecto al mundo jerárquico europeo, está pensando en la forma de como se observa la escritura fonética o las imágenes europeas en términos occidentales, o está observando contraponer ciertas ideas que también se han creado y se pueden re-crear desde el Perú prehispánico?

JG: En última instancia, de hecho los europeos valoran moche, sobre todo, por su capacidad estética. Por ejemplo, Pablo Picasso, él mismo ha tratado de recrear moche y ha construido dos vasijas en arcilla tipo moche. ¡iPablo Picasso!! Pero también Picasso, ha dicho que el arte que más le ha impresionado en la historia del arte es ChavínCupisnique. Vemos que hay una percepción desde allí que valora las culturas antiguas del Perú de una manera completamente diferente a la que prevalece acá. Y esto de alguna manera es importante. Estamos viviendo en una cultura globalizada y también el reconocimiento de los logros culturales ha sido mutuo. Pero, en cierto grado yo pienso que moche para el Perú es bastante importante porque esta cultura, socialmente, es una de las sociedades más complejas que se han desarrollado en el Perú antiguo. Por lo menos comparable con los incas, y en muchos aspectos quizás más diversificado que lo inca. Porque, la cultura moche tiene amplio sentido de una cultura urbana, con una gran población urbana con una división del trabajo urbano, con problemas de administración bastante complejos, entonces moche a este nivel, tiene más enlaces con el presente, donde el Perú se está urbanizando, que otras culturas que han quedado más bien, incluso en el pasado, en una cultura aldeana básicamente de campesinos. En la cultura moche hay 
que ver que más o menos el cincuenta por ciento de la población no son pescadores, no son agricultores sino es población urbana, que es algo excepcional para una cultura tan antigua. Y eso también lo privilegia frente a Nazca. Éstos, simplemente por la extensión de las áreas irrigables de la zona no pueden desarrollar una cultura urbana tal como lo podía hacer moche, que tiene todavía áreas de irrigación, de doscientas mil hectáreas, por unos valles y eso permite tener, en un valle una población enorme, como tenían las fuentes alimenticias tanto con proteínas que venían del mar más la agricultura tenía una buena base para desarrollar culturas urbanas. Este es quizás lo que también conduce un poquito a que uno privilegie moche. Sin embargo, otras culturas como TiahuanacoWari, hay que considerarlas también porque los habitantes del altiplano básicamente eran los transportistas, desde fines de la época Chavín, para todos los andes. Esta cultura Tiahuanaco-Wari son los grandes comunicadores. Por esto, moche parece relativamente aislado, Nazca, Recuay, la cultura Lima parece relativamente aislado, lo que no es cierto porque habían los caravaneros altoandinos que les traían todos los insumos que ellos necesitaban, que es la razón por la cual se nota en ese periodo que se denomina Intermedio temprano. Un aumento de la productividad especialmente en la artesanía es completamente fenomenal. Los moche producen durante los cinco o seis siglos de su existencia, veinte veces lo que produjo todo el desarrollo anterior de Cupisnique en adelante, en cuanto a cerámica e imágenes de cerámicas que realmente es un aumento de productividad completamente extraordinario que tiene que ver con que tenían a otra gente en las zonas altas del Perú para transportar la materia prima. Pero el acarreo de la materia prima, también le da un privilegio para difundir, para comunicar esquemas de organización. Tiahuanaco toma primero los modelos de la costa, después los trabaja, los sistematiza, y los redistribuye lo que finalmente termina si se quiere, en el final de esas culturas del Intermedio temprano porque aparece el fenómeno de que todas las culturas peruanas tienen una influencia fuerte de los caravaneros, lo que llaman Wari en el Perú. Es decir, hay todo un engarce allí, y quizás para terminar este recuento un poquito, en esta época, allí del Intermedio temprano incluyendo a Wari, se desarrolla un espacio cultural integrado básicamente por los caravaneros, en los cuales se crea una cierta similitud en las formas de pensamiento en todos los andes. Incluso un espacio interconectado en todos los andes, que es en realidad el espacio que el estado inca, en su rápida expansión está reconstruyendo con nuevos modelos políticos. Es decir, en realidad los incas, se desarrollan sobre un espacio constituido, mil años antes, y lo tratan de organizar con una economía que tiene como centro el Estado. Pero los incas, en ese sentido, son herederos de un espacio, y de una cultura unificada. Me acuerdo que Alfredo Torero, el lingüista, demostró que el quechua llega al Ecuador, no en la época inca sino en el Intermedio temprano. De allí se construye ya la gran extensión, y eso hay que tener bien presente allí. Los incas han sido reducidos a ser algo así como una sociedad excepcional que crece con gran velocidad, pero solamente tiene esa posibilidad, porque en realidad, el espacio, incluso las interrelaciones dentro del espacio ya están constituidas.

PJP: Precisamente, había ya una base pre-moche que de alguna manera se había constituido desde un punto de vista económico, iconográfico o simbólico, entonces ya había algo sobre el cual se podía reproducir una cerámica mucho más avanzada, de tal manera que en realidad, se dan el lujo de hacer una iconografía muy sofisticada, entonces, si lo vemos así, ¿los moches construyen un modelo o simplemente son una forma de mediación frente a las culturas que terminan y empiezan?, ya que una vez que moche se 
derrumba, esta iconografía, estas estructuras en las imágenes se pierden, ¿cómo puede explicar esto?

JG: Primero hay que ver que moche, si uno lo quiere mirar del lado de la historia larga es algo como un Cupisnique tardío, es decir, como que hay antes de los moche como tres mil años, que van delante en lo cual se desarrolla la sistematización del conocimiento $\mathrm{y}$, su expresión en un sistema semántico, que en Cupisnique es bastante parecido a lo de moche, solamente que los moches perfeccionan gracias a la tremenda destreza de los artesanos, perfeccionan la finura de la transmisión del mensaje, es decir, los moches pueden ubicar en una vasija a cincuenta personajes, mientras los recursos técnicos de los Cupisniques, quizás te ponen dos, tres, cuatro personajes en una vasija. Entonces, se puede ver en Cupisnique que los elementos básicos de moche están presentes, el orden básico está presente, pero la complejidad de los mensajes es mucho mayor en moche, es decir, allí quiere decir que especialmente en las fases moche $I V y V$, logran una capacidad de expresión que no se alcanzó antes. Y, es más, uno puede percibir, si se analiza bien, que en los principios del desarrollo mochica hay una presencia de los esquemas mentales. Incluso, hay una presencia de las narraciones que se puede rescatar del material moche pero su expresión es muy gruesa. Es decir, yo puedo mostrar una vasija de moche I, o de moche II, que muestra que, por ejemplo, un ciclo narrativo tiene en moche mil detalles. Eso está presente y se expresa en una figura, donde se puede ver que esa figura, en realidad es parte de una narración que posteriormente se expresa en una secuencia de los cientos de imágenes. Allí se puede notar simplemente un refinamiento extremo, es decir, son unos maestros que deben haber trabajado en talleres donde había una selección de calidad y de capacidad de los productores, muy extraordinaria pero no deben haber sido tantos talleres que hacían las vasijas excepcionales. Talleres más bien de tipo familiar donde se abren de una generación a la otra en la destreza para hacerlo pero el hecho de la rapidez con la cual desaparece la sofisticación del arte moche, muestra un poquito que deben haber sido unos tantos talleres que desarrollaban ciertas destrezas, pero allí, cuando de repente se produce un cambio político y un cambio de gustos en cierto grado decae rápidamente y desaparece. Pero hay que ver que los logros de moche en su expresión todavía se pueden encontrar en Chimú. Estos llevan los mismos mensajes, pero de una forma completamente abreviada, como que ya se socializó en la época anterior todo el conocimiento y entonces solamente tienen que poner una figurita sobre un huaco simple, y ya se sabe en qué se está. Pero las formas de construcción de sentido de Chimú, son eco de las cosas muchas más sofisticadas de los moche.

PJP: Y, estos conocimientos, ¿lograron desarrollarse, aparte de los Chimú como refiere, en las otras culturas como en Tiahuanaco, en Nazca, o simplemente ya no existe la continuidad moche, quedando rezagado a su espacio y su tiempo ya que una vez que se acaba, decae toda esa iconografía tan maravillosa y tan fina que usted describe?

JP: Mira, en realidad, es ligeramente más complicado porque quizás el medio de expresión más importante de los andes, especialmente a partir de Tiahuanaco y Wari, no es tanto en la cerámica, sino en los tejidos. Y, de los tejidos moche conocemos muy poco, porque el clima de la costa norte no ha ayudado a su preservación, pero podemos ver ya en Paracas que, incluso antes del tiempo de los moche, hay una gran sofisticación de la expresión de tejidos. Y lo mismo hay que pensar de moche donde debe haber existido una gran 
sofisticación en la producción de sentido en los tejidos, pero se perdió, y simplemente porque no se mantienen los materiales orgánicos en ese clima de la costa norte que tiene lluvias de vez en cuando, y entonces, se ha mantenido lo no orgánico pero los materiales orgánicos se han perdido en amplia medida. Bueno y viendo esto, es probable que tanto en Tiahuanaco, y eso sí se puede demostrar, especialmente con los hallazgos que se han hecho en el norte de Chile, como en la zona Nazca-Paracas, ha habido una sofisticación bastante grande, en las expresiones textiles. Y los textiles de alguna manera permiten, como son superficies muy grandes, llegar a una sistematización mayor en un medio de soporte. Incluso hay tejidos Chavín que se ha encontrado en la zona de Paracas, que muestran que hubo una elaboración muy compleja de la interrelación de los seres de poder en las divinidades Chavín, muy tempranamente. Es decir, los tejidos se prestan más para esto. Y, después de moche si bien este estilo de cerámica se pierde en buena cuenta, hay que ver que sigue habiendo, un desarrollo, por ejemplo, en Tiahuanaco, que es altamente sistemático, no tanto con moche en la exposición de narraciones, pero sí es altamente sistemático en la expresión de las relaciones parentales entre los diversos elementos del universo, allí son tremendamente sistemáticos, y es que se puede leer, como una escritura los signos que utilizan para expresar la interrelación entre las divinidades diversas.

PJP: Es que se trata de una sociedad ágrafa que los europeos lo ven muy lejos, en las antípodas, es una sociedad sin escritura, que además usted trata también de explicar en su libro, es decir, como los moches, no pueden simbolizar un conocimiento social en términos de signos o fonemas a modo del mundo occidental, entonces, a esta población lo único que le queda es la iconografía, donde se describen imágenes con un pensamiento cósmico, conflictual, guerrero, todo un pensamiento de la vida cotidiana, productivo, y además pues, bastante cultural.

JG: Ese es un problema complejo, el año pasado se publicó un libro Moche art and visual culture in ancient peru, de una señora norteamericana, que ahora está en Stanford, que se llama Margaret A. Jackson. Ella dice que moche es un sistema semántico comparable a una escritura y la compara con la escritura maya, la compara con la escritura china, y en ese sentido el umbral entre lo que los europeos entendían como escritura es básicamente una escritura fonética; y una escritura de imágenes como la china y la iconografía moche es muy difuso, es decir, en realidad los moches eran tan sofisticados en sus sistemas de exposición que uno puede construir sentido, y no solamente esto, sino uno tiene un sistema básico, de organización de sentido de las cosas que permite ubicar, algo completamente nuevo sin mucho problema en el universo pensado preexistente. En ese sentido, es como un sistema simbólico, que permite constantemente incorporar contenidos nuevos. Y esto ya va más allá de una simple iconografía, es algo así como un sistema de ordenamiento, un instrumento filosófico que dice allí viene algo nuevo y esto pertenece acá. En ese sentido, yo pienso que en el caso de moche es visible de igual forma en Tiahuanaco y Nazca; también supongo el sistema inca donde se han seguido varias líneas para perseguir cómo utilizaban medios para almacenaje de información y de expresión y transmisión de información. Toda esa discusión sobre lo ágrafo hay que abrirla nuevamente en el sentido que no es tan importante, ágrafo viene del griego, no escribir como los griegos. Entonces, hay que discutir un poquito más qué es lo importante. Lo importante es transmisión de información en medios adecuados, es decir, donde un emisor y un receptor se pueden entender a través de un medio y si 
se ve el problema básico definido de esta forma, visiblemente, los moches tenían un sistema para pasar información de un emisor a receptores bastante coherente, que se mantiene a lo largo de siglos. Entonces, el moche del S. VII que encuentra un huaco del $S$. II, entiende perfectamente qué tiene delante de sus ojos. Incluso eso es interesante, en el Brujo en el valle de Chicama se encontró una tumba donde se había enterrado a una sacerdotisa, es una tumba reutilizada, donde se saca los huesos del anterior se le pone el nuevo con sus nuevas vasijas pero también se ponen las antiguas, porque sabían que cabían en ese contexto. Es decir, eran comprensibles a través de varios siglos, y eso significa que es un sistema de expresión bastante pautado, que sirve para las cosas y hay, que ver que esta gracia de los sistemas de escritura como la escritura cuneiforme, la jeroglífica egipcia, la griega, la cretense o finalmente la romana tienen una base mayor para personalizar información, es decir, como dicen los latinos, se puede transmitir la obra de una persona. Pero esto es una cosa relativa, porque en sociedades como la moche, la china, la japonesa o la hindú, el individuo no tiene esa importancia que tiene en el pensamiento europeo. Entonces, para la sociedad moche o para la sociedad hindú o la china, es más importante la transmisión del sentido general de la totalidad que ese dato personal: que ese señor que, vivió en tal y tal fecha, y murió en tal y tal fecha, e hizo la batalla por allí. Esto no importa mucho porque todo es incluido en un pensamiento que engloba las cosas, organiza las cosas, sistematiza las cosas y eso es lo importante para la transmisión. Allí uno no debe de ser eurocéntrico y tampoco en lo que debe ser el contenido de lo transmitido. Esto está en función del tipo de sociedad, como por ejemplo, en nuestros tiempos nuevamente puede haber una población si se quiere ágrafa, que recibe información a través de la televisión y a través del lenguaje hablado y puede ser perfectamente informado por un discurso hablado y con las imágenes, ya no necesito la posibilidad de leer. Se sabe por ejemplo que el veinte por ciento de los norteamericanos son funcionalmente ágrafos, analfabetos, pero están bien integrados a su sociedad porque allí están los medios visuales y los medios hablados, sonoros, que permiten integrarlos perfectamente bien. Y allí se puede ver que lo de la escritura que se dio tanto énfasis, después de la revolución de Gutenberg en Europa, es algo que está bien en cierto contexto histórico social, en cierto tipo de sociedad, pero en otras sociedades como la nuestra ya no tiene tanta importancia.

PJP: Cuando se lee su iconografía moche, se ve que pone mucho énfasis en los enfrentamientos, en las confrontaciones de las divinidades, es decir, se observa la prioridad en estas imágenes, como lo hacen las ciencias sociales estructuralistas, desde las deidades y sus sentidos de oposición y complementariedad, ¿esto porque existe una relación directa con lo que se produce en moche o es la manifestación de una cosmovisión más amplia y hasta astronómica de esta cultura?

JG: Las sociedades del Perú antes de la llegada de los españoles, quizás si uno se fija bien de cuán importante son las relaciones de parentesco para tener usos de poder en el gobierno peruano, la sociedad antes de la llegada de los españoles está claramente vinculada a una organización por sistemas de parentesco y, todo eso de las divinidades, en realidad, es una expresión compleja, del desarrollo de un mundo complejo, a partir de unas divinidades que permiten la jerarquización del mundo social y a través de esta jerarquización de las divinidades, y la idea de que todo lo existente, los humanos, la naturaleza son descendientes de ese mundo primordial divino se le da algo así como orden natural, a las diferencias sociales incluso a la división del trabajo. Entonces, si bien en las 
imágenes aparecen las divinidades hay que ver que ya los señores se representan frente a la sociedad como descendientes de la divinidad " $X$ ", o descendiente de la divinidad " $Y$ ", de esta forma se legitima el poder con una idea sobre un pasado primordial donde se construye la diferenciación social y la división del trabajo y, por esto es que hay un énfasis sobre ese orden primordial porque justifica la diferenciación del presente. Y el rol que tienen los diversos subgrupos de la sociedad en la perpetuación del orden. Ese es una idea que los moches deben haber tenido de manera muy extraordinaria, que ellos por las interrelaciones entre los diversos grupos sociales, tenían que coordinar para que se produzca bien el futuro. El sentido de los ritos moches, como se puede ver, es organizar la producción del futuro a través de la interacción social. La idea es bastante sofisticada, tienen a diferencia de la manera europea de construir historia, construyen historia en un modelo de genealogía, incluso las plantas, los animales, todos están relacionados con esta genealogía, lo que se puede ver mejor en Tiahuanaco, donde se ven diversos tipo de pajaritos, plantas, todo esto con signos que los ubican claramente en el sistema parental. Y también en Nazca en cierto grado se puede ver esto, es decir, el parentesco es como el modelo básico de hablar sobre la historia, y de hablar sobre el futuro, y las divinidades como los símbolos, son los que permiten explicar el porqué de las diferencias de los grupos, y al mismo tiempo ese es quizá en lo central: permite crear una jerarquía que una vez aceptada por la socialización ubica a cada uno en un sistema de organización social donde uno acepta el lugar, en la sociedad en el cual uno nace. El cual uno tiene adscrito por sus antepasados. Los antepasados determinan, yo estoy aquí, y ese está acá, no puedo pensar, que he nacido en una línea de parentesco, que si yo soy hijo de pescadores no puedo soñar que me voy a volver agricultor, o que me voy a volver artesano, y menos aún que voy a cambiar de condición social y me voy a convertir en señor. Simplemente no, ya y allí hay que ver la construcción del presente. La construcción mental del presente, que es diferente a la construcción mental que los europeos hacen del presente, quizás con excepción de los fundamentalistas actuales que dicen, que el presente está constituido por una creación divina y cada uno y el orden tiene que ser como está escrito en todos los textos de la biblia. Solamente que la biblia en ese sentido no es sistemática, mientras el sistema moche es profundamente sistemático en el tema del parentesco y esto no es casual porque efectivamente, desde épocas muy tempranas, hasta antes de que se comiencen a desarrollar las sociedades complejas, la gente estaba organizada parentalmente, por lo que no es casual que desarrollen una justificación de las jerarquía social a partir de bases parentales, y que utilizan esas jerarquías, para crear algo así como una naturalización de las diferencias sociales. Porque necesitaba la jerarquía para manejo de la sociedad y al mismo tiempo no tenían, una fuerza policial para poner al lado de cada uno un soldado que le obligue a hacer lo que tenía que hacer, es decir lo tenían que pasar a la cabeza de la gente y la gente una vez que aceptaba las categorías parentales que aceptaba su descendencia en ese sistema, aceptaba su rol social. No se podía escapar de esto. No había alguien que gracias a su esfuerzo, personal, intelectual, ciudadano libre ocupe un espacio social que tampoco, es tan cierto hoy pero, en la época moche impensable.

PJP: Y aquí viene otra cuestión, porque precisamente esa jerarquización, muchas veces pensada a partir de esa iconografía, es excepcional, se nota muy claro, pero dentro de esa misma explicación, trata de establecer la búsqueda del tinkuy, entonces, ¿dónde está esa relación entre esta jerarquía social y la búsqueda del tinkuy, desde las mismas divinidades? 
JG: Mira, todo sistema social y, especialmente un sistema social jerárquico, es un sistema de inclusión en diversos escalones de poder, para cada grupo y de exclusión de otros, en los escalones de poder. Entonces, el tinkuy, es algo como que permite, a pesar de que básicamente es un sistema de exclusión, presentarlo como un sistema de inclusión, es decir, la conjunción de los opuestos es necesaria para que se pueda producir futuro y allí está la importancia del tinkuy, es decir, que es el instrumento que sirve para la inclusión. Incluso se puede ver, más en el sur andino, en Bolivia, se puede ver todavía hoy esas batallas campales medio rituales, que donde las mitades del pueblo se dan de alma, y el fin es que por lo menos maten algunos, que también es una especie de tinkuy. Un tinkuy confrontacional, y los mismos que hacen ese tinku confrontacional que se tratan de romper la cabeza, la otra mitad del año está cobrando, es decir, toda esa idea de la división del tiempo en dos periodos, uno en un tinku confrontacional, y otro de un tinku consentido. Es un esquema muy sofisticado si se quiere, de manejar las contradicciones sociales en un sistema de inclusión y exclusión a la vez. Y allí está la importancia del tinku, no por la belleza sino es un sistema muy sofisticado. Casi diría que es abstractamente como modelo social, es mejor logrado que el de nuestra sociedad. En nuestra sociedad se les dice a todos: somos iguales, somos iguales no hay ningún problema, y al mismo tiempo, la gente vive en su propia carne diariamente la jerarquía social, su exclusión, donde no hay mecanismos para incluirlo. O salvo un discurso muy abstracto que dice en la Constitución, "somos todos iguales", pero el pobrecito que camina por la calle dónde se puede incluir. Porque ese discurso no le dice mucho, además él bien tiene presente que ese discurso le dice que no hay igualdad. Y allí los moche más sofisticados de alguna manera ritualiza la división social y al mismo tiempo la inclusión de los opuestos. Incluso la inclusión, de niveles jerárquicos, a través de un sistema filosófico, si se quiere muy complejo. Y quizá a eso se pueda añadir que si bien hay un énfasis en las divinidades los moches, al mismo tiempo y no solamente ellos, sino eso se puede ver muy bien que es bastante similar en casi todas las culturas andinas, desarrollan algo así como signos más abstractos, símbolos, donde las ideas básicas del modelo del mundo ya no se expresa en figuras de divinidades o algo así, sino simplemente en signos, entonces, de alguna manera por ejemplo, los tocapu inca, se pueden entender como una independización de los signos que ya no requiere tanta imagen, sino que son los símbolos que se han desarrollado antes, miles de años, que la gente entiende. Mucho también lo que hasta hace poco, incluso hoy, en alguna parte siga viendo símbolos en tejidos, son símbolos que se pueden entender, que pertenecen a ese sistema filosófico. Entonces, hay una gente que trabaja en esto, pero son por lo normal gente entendida en textilería que está más fijados en el objeto en vez de fijarse en la sociedad y la función que tiene el objeto en la sociedad, es interesantísimo esto. Y habría que perseguir más estas pistas. Hay que decir que mal o bien, la antropología peruana que al principio tenía esto, tanto la arqueología como la antropología con todos los avances que hizo en los años sesenta, también perdió parte de su tradición que veían estos aspectos, quizás de una manera inadecuada, pero hubiera sido lo que se hizo hasta allí, una buena base para seguir indagando, pero como hubo una influencia exterior muy fuerte, que insistía en otros discursos, uno puede ver, en principios de los años sesenta, que tanto la arqueología como la antropología deja unas pistas para privilegiar otras que vienen del exterior. Es una pena, y este libro también quiere contribuir a rescatar esto. El libro si bien está dedicado a algo que parece un objeto del pasado, de muchas maneras quiere contribuir al presente y al futuro, y era muy sorprendente la presentación que se hizo del libro en el Cusco, donde había un grupo de campesinos, más o menos grande, en 
la presentación, que ellos después comentaron, y eso me escribieron ya del Cusco, que decían: "no sabíamos que lo nuestro era tan antiguo". Es decir, los cusqueños de hoy habían visto lo que yo les mostré en imágenes, que era algo de ellos. Y eso me parece sumamente interesante, es decir, que la gente que está a mil kilómetros de los moche, se reconoce en los moches. Incluso como les mostré, también que los moche no vivían solo en su espacio de los valles norteños sino también por ejemplo, conocían la selva, también conocían el sur andino. En realidad, hay que pensar que esta idea, que hay un poco en la arqueología de una sociedad en su territorio es una idea equivocada, es decir, es una sociedad que utiliza un estilo propio, para marcar fronteras frente a otros rumbos sociales, pero al mismo tiempo es una sociedad que conoce ampliamente el espacio, que trasciende en todo, por ejemplo en su artesanía, trasciende en su medicina, trasciende en este espacio de los valles norteños, toda la medicina de la costa norte se basa en la medicina de la selva hasta hoy. Cuando uno busca un curandero en la costa norte, básicamente tiene semillas de la selva, y no tiene algo de la costa norte, es decir, hay una continuidad allí, en una integración mayor en la medicina que la integración en un espacio, que se reconoce como políticamente unido y que marca su frontera, en un estilo específico de expresión que es reconocible como las vasijas moche. Es un estilo que marca fronteras frente al otro grupo social. Pero la existencia de las fronteras no significa, que uno no viaje, y que uno no tenga relaciones y, que uno no esté presente mucho más allá de las fronteras, del entorno político al cual uno se inscribe.

PJP: En las imágenes que usted propone y que de alguna forma ha tratado de rescatar, se observa también lo tétrico con dibujos tenebrosos, por ejemplo esto de las bubas en el cuerpo de un personaje, como una forma de tenebrosidad que tratan de imponer, ¿esto, expresa manifestaciones que se relaciona con algo divino, o al revés tiene más bien que ver con algo mucho más social, con una sociedad que de repente está pasando por una serie de penurias, enfermedades y muertes?

JG: El asunto es que primero, que por supuesto que conocían enfermedades, que conocían discapacidad en muchas personas, hay muchas imágenes de esto, y no necesariamente porque hubo una gran cantidad de discapacitados en la sociedad moche sino que veían a los discapacitados como intermediadores entre los mundos. Entonces, como la intermediación entre los opuestos les eran importantes, muestran figuras humanas que tienen la capacidad de intermediación, por ejemplo los ciegos en el mundo de la superficie, pero, según la concepción moche, no solamente moche, en Nazca se da lo mismo, los ciegos pueden ver el mundo de abajo. Es decir, son comunicadores, y por esto hay un énfasis en esos siglos o por ejemplo, en esto que dijiste de los bubos, que hay allí en un cuerpo de un personaje. Es un personaje especial que por línea materna, pertenece al mundo de abajo y por línea paterna pertenece al mundo de arriba y de allí tiene la capacidad de moverse entre los espacios y entonces tenemos narraciones que la muestran moviéndose entre los espacios donde él pasa un periodo largo, en el mundo subacuático, que pertenece al mundo de abajo, y que en la construcción mental de los moche es un espacio más bien femenino, y él pasea por allí siendo masculino. Entonces, como está mucho tiempo en el espacio femenino de alguna manera el cuerpo se contagia con lo femenino, y cuando sale del mundo subacuático, tiene de lo masculino y de lo femenino, en realidad de las cosas opuestas. Entonces le salen esos chupos, que están allí, se rasca, se muestra mucho en la imagen, pero esto lo que se rasca se recolecta en un plato, y son semillas. Semillas que ha podido crear porque tenía de las dos cosas, lo 
femenino y lo masculino. Es una capacidad de creación porque, junta en su persona por las aventuras que tiene allí en el mundo subacuático, junto a los opuestos, puede generar semillas que son importantes. Y, al final de sus días si se quiere, se eterniza en el cielo, y cuando se le representa en el cielo, aparece como el personaje del cuerpo, del cual salen plantas en todas las direcciones, es decir, es un personaje, para utilizar esa palabra quechua o también aymara, es un personaje tinku, que en sí tiene ambos extremos del mundo juntos y por lo tanto, tiene una capacidad generativa extraordinaria. Y por eso también es algo así como un ser que especialmente en moche $I V$ y moche $V$ aparece como casi el centro de todo la imaginería, porque para los moche la reproducción especialmente la agraria era algo primordial, entonces este era el personaje que gracias a sus aventuras, si se quiere, les daba la posibilidad de tener una múltiple instancia de idea.

PJP: La muerte está bien marcada en la sociedad moche, es decir, tiene mucha representatividad, incluso en las imágenes tienen algo así como una continuidad, es decir uno observa constantemente calaveras, así como también los bailes de los muertos permanentemente, ¿se trata de una comunicación entre muertos y vivos?, ¿por qué, de manera constante, la representatividad de los muertos?

JG: Primero, por la importancia que tienen los antepasados que son los que han generado el presente, eso como el Japón de alguna manera. Los del presente tienen una gran deuda con el pasado porque allí están los antepasados que les han dado la vida. Por eso los muertos, son producto de veneración. Pero segundo, porque en la concepción moche, el que deja esta vida en la superficie, pasa a otro espacio donde las cosas se desarrollan al revés, digamos mientras en el mundo de arriba yo envejezco, en el mundo de abajo el muerto se vuelve más joven y, finalmente regresa a la superficie y algo así como la esencia del muerto es decir, en ese sentido, hay una integración entre el espacio de los muertos y el espacio de los vivos. No es como en la cultura occidental donde se ve que los muertos se despiden, se vuelven tierra, en la acepción laica o la acepción cristiana, bueno allí esperan el juicio final para irse al infierno o al cielo; sino, lo contrario, es decir, se requieren de los muertos para que pueda funcionar la vida de los vivos, los muertos son la base para que haya la comunicación cotidiana entre los mundos, la base parental. Mis muertos tienen que cooperar conmigo para que crezcan las plantas, algo así como que yo tiendo arriba las plantas pero los muertos tienen que empujar de abajo para que se vayan para arriba, es decir, es una idea muy diferente a la actual que más bien trata de esconder la muerte, y privilegiar la juventud. Ellos, primero generan a la gente vieja porque ya se va a pasar al reino de los muertos. Y segundo, tienen muy consciente la presencia de los muertos, porque necesitan de la cooperación de los muertos para que la vida en la superficie terrestre funcione. Los dos tienen que juntarse bien. Por allí, les hace tan importante que los muertos lleguen bien al reino de los muertos, y que estén bien alimentados por eso es que hay unos ritos de alimentar a los muertos, en ciertas fechas del año para tener allí sus muertos, que tienen que cooperar con ellos, porque nuevamente entre muertos y vivos funciona el parentesco. No son los muertos en general, sino son mis muertos, iimis muertos!!, que son los que me ayudan, por esto yo tengo que preocuparme porque mis muertos lleguen bien, que mis muertos no hayan dejado en la superficie de la tierra deudas, que impiden de que se vayan al mundo de abajo. Es decir es toda una forma de asegurar el cumplimiento de la normatividad social, porque el no cumplir con la normatividad social significa que no puedo recorrer bien los pasos del camino al reino de los muertos, entonces, me 
quedo vagando por allí por algún sitio, no puede llegar bien al reino de los muertos y, no llegando al reino de los muertos sus descendientes en el presente están como que no tienen parientes abajo y no funciona bien su vida.

PJP: Da la sensación de que el tinku en la sociedad moche, en realidad está por el lado de lamentos o de penurias, de enfermedades o de muerte, que de alguna forma las sociedades occidentales, lo observarían de manera negativa; pero también usted lo rescata por el lado de la diversión, como se observa en el baile de la soga o el baile de los danzantes, o por el lado de los juegos como en el juego de los frejoles, por ejemplo, y a la vez también lo trata de ubicar en las asas de las vasijas es decir, ¿dónde está esa diferencia si en algún momento lo busca en la muerte, en las enfermedades en otro momento lo ubica en la alegría, en el juego, y en otro tratando de mirarlo en la ese ("S") o en las asas de las vasijas, en realidad, existe por allí un tinku que aglutine de modo continuo y siempre un tipo de apertura en nuestra sociedad?

JG: En realidad, también tenemos que desvestir nuestros conceptos de la alegría y de la tristeza porque son después de todo, conceptos de nuestra sociedad y no de la sociedad que creó esto. Por ejemplo, una cosa interesante es que los muertos en muchas imágenes moche aparecen bailando, incluso algunos como que están conversando alegremente ${ }^{3}$, están como jugando, entonces uno puede ver que es una concepción de la muerte bien diversa a la que nosotros podamos tener. Y también el juego, es qué sé yo, me voy a la computadora y me cargo el juego que alguien ha desarrollado, mientras allí, como no es una sociedad que ha pasado por el siglos de las luces donde se separa la religión de la vida diaria, si lo integra la percepción si se quiere metafísica-física, de todos los fenómenos en un sistema, no hacen la diferencia entre muerte y vida, no separan el juego del ritual. El ritual al mismo tiempo es un juego, y casi sospecho que cuando hacían sus escenificaciones en los rituales se deben haber matado de risa muchas veces, pues era parte de su vida, como hoy en día cuando uno va a las fiestas andinas a los occidentales les choca que la gente en las fiestas andinas, se está emborrachando a más no poder. Y, entonces piensa que son borrachos como el borracho parisino que duerme debajo de un puente, un asocial por allí, pero no; para los moches, el emborracharse significa llegar a un estado mental, que les permite comunicarse con las divinidades, y también los antepasados. Y entonces, uno ve en las grandes fiestas de los cristos diversos, que hay en los andes, que la fiesta en parte es borrachera, pero es la búsqueda de la comunicación con la divinidad a través del estado etílico ${ }^{4}$. Es decir allí, la idea es completamente otra solo que la borrachera, y allí no hay que caer en el etnocentrismo y pensamos en borrachera y borrachera, no es así. Es interesante esto.

PJP: Si nosotros coligamos, la muerte con la fertilidad de manera relacional, ¿cómo asociamos allí la mujer moche? Refiero esto que está bien marcado si observamos etnográficamente a la mujer moche actual en Trujillo y más hacia el norte peruano, donde uno ve a una mujer norteña con pautas culturales en sus quehaceres, como en la artesanía o el tejido, o en otras mujeres la siembra y la cosecha en la chacra, o en otros casos el comercio en la mujer, es decir, yo diría que desde ese sentido de fertilidad y muerte da la sensación que están un poquito lejos, si lo ubicamos actualmente con estos "nuevos" patrones socioculturales.

3 Risas de los interlocutores.

4 Risas de los interlocutores. 
JG: Siempre hay una diferencia de géneros, si yo lo veo desde la investigación de la relación de poder, entre los integrantes femeninos y masculinos de la sociedad. Pero, la primera atingencia que hay que hacer, es que para toda la gente de los andes y no solamente para los moches, la unidad social básica de la sociedad: uno se vuelve ciudadano formando pareja, es decir la pareja es la base de la sociedad y no el individuo. Y entonces hay que ver que un poquito allí, se relativiza eso de la diferencia de género porque la pareja es la unidad social básica. Eso es importante entender, y hay una división del trabajo muy clara entre el ámbito en el cual tiene poder la mujer, y el ámbito en el cual tiene poder el hombre. Y hasta hoy en día se puede ver muchas veces que eso tiene consecuencias en la modernidad actual, de manera visible. Por ejemplo, la mujer en las culturas campesinas andinas ha sido la encargada de la despensa, y parte de la despensa era conseguir los alimentos para poder preparar los platos cada día, y de esto nace que a la mujer le corresponde la función de conseguir por intercambio otros bienes que se necesitan para la despensa. Y con el desarrollo mercantil, esta función de la mujer se vuelve mucho más importante, entonces uno puede ver por ejemplo en el altiplano, la cultura aymara y también en la cultura huanca que las mujeres muchas veces conocen más del mundo, especialmente del negocio, que los hombres. Y es una gracia de este mundo ligeramente machista, que esas mujeres de poder, que hay por ejemplo en la sociedad aimara o en la sociedad huanca, son conocidas en la sociedad ligeramente machista como mujeres feas, es decir por tener más poder que los hombres, y una mujer que tiene más poder que los hombres, a la gente que está más acostumbrada a que los hombres ejerzan el poder, tiene que ser mujer fea. Es un poquito como hoy en día existe una imagen de las argentinas en el Perú, que son mujeres más aguerridas, de más poder, de más emancipación, que los peruanos le dicen son un poquito feas. Lo mismo dicen de las mujeres huancas, de las mujeres aimaras, son feas. Es decir, allí se utiliza un concepto estético para combatir el mayor poder que tienen esas mujeres. Y allí hay que entender que de hecho las imágenes moche privilegian a los hombres, especialmente en las pinturas. En las imágenes esculturadas hay mucho más presencia del lado femenino, y esto es quizás lo más interesante, cuando haya representaciones del espacio de los muertos del reino de los muertos. Allí está toda la familia, están las mujeres, los hijos, todo; mientras, en la vida de la superficie aparecen primordialmente los hombres. Es decir, hay que matizar, también allí un poquito la percepción de la relación de los géneros y hay que pensar por qué representan al reino de los muertos como un mundo muy familiar con chicos, con grandes, con hombres y mujeres y el mundo de la superficie mucho más con hombres que interactúan en manera de guerreros, sacerdotes. Hay sacerdotes femeninos pero, de hecho en la vida en la superficie, que representan los moche en la pintura en línea fina hay una preponderancia de mujeres de manera extraordinaria. Pero este, que es un huaco en la superficie que tiene una forma de papa, es un huaco enorme ${ }^{5}$. Muestra una relación muy interesante entre el hombre y mujer, si se voltea un poquito la vasija se ve una pareja en coito, y es una divinidad femenina que se junta con un campesino y, lo que hace el campesino es fertilizar a la divinidad, que muestra un poquito que por lo menos para el mundo de abajo, la relación para con el mundo de arriba tiene una inversión, es decir el personaje de poder que está en el mundo de abajo y el campesino puede fertilizarlo, con su palo de plantarlo o como sea.

5 Se refiere al dibujo de la carátula de su libro. Ver imágenes. 
PJP: He tratado de observar los dibujos donde también sobresalen mucho, la rana, el zorro, la garza o el aspecto del felino que siempre están allí, digamos casi permanentes y presentes como mediadores o también siendo parte de una oposición, ¿Se observa también allí una visión mucho más integral entre el hombre, la naturaleza y la sociedad a partir de los animales?

JG: Primero, para los moche todos están emparentados, es decir los humanos no son una especie por sí y allí están los otros como sería en la aceptación actual, por lo menos no en la biológica. En la biológica sí estamos emparentados todos. Pero en la aceptación diaria es algo así como que los humanos son algo completamente diferentes a los animales, pero para los moches y supongo para la mayoría de culturas prehispánicas hay un parentesco general entre todos los seres incluso en los seres inanimados de los seres animados, de plantas y diversos tipos de humanos. Entonces, uno puede ver que también las plantas pertenecen a ese sistema de parentesco, también los animales diversos se ubican de manera diversa en el universo según sus parentescos. Y la relación entre humanos y animales, se da por el parentesco que tienen. Es decir, los pescadores descienden de una ballena, y los peces también descienden de la misma ballena, entonces, la relación entre pescador y pescado es en realidad una, que es oportuna porque son parientes; es decir, es interesante esto que realmente o también por ejemplo las plantas son parientes de los agricultores, y por eso tienen la capacidad de cuidarlas bien o de pescar bien. $\mathrm{O}$ cosas por el estilo o también es interesante los alfareros moche están ligados al mundo de abajo, porque la arcilla viene del mundo de abajo, entonces tienen un orden de representación para las cosas de la superficie, que es la pintura en línea fina, pero cuando ves la representación del mundo de abajo, es mucho más en escultura donde la arcilla toma su forma, porque la arcilla es parte del mundo de abajo. Incluso, cuando hay imágenes, diseñadas así complejas son más bien de bajo relieve, o moldeados y no pintados, es decir, es como que la arcilla toma su forma. Allí se ve la sofisticación del asunto, es la imagen referida al mundo de abajo, es otra forma de expresión en relieves, o en esculturas que la imagen que representa al mundo de arriba porque el material en el cual se expresa está relacionado con los ámbitos diversos. Y entonces, según el origen del material, la representación de imágenes entre otras formas es realmente impresionante la coherencia de esa forma de pensar sobre el mundo. Quizás lo que más me impresionó en el caso moche es que es un sistema altamente elaborado, muy sofisticado con una coherencia extraordinaria en la construcción de sentido.

PJP: Una última imagen que se descubrió en una de las paredes ceremoniales en la Huaca de la Luna, logrando una pequeña conversación con unos pescadores moches y, preguntándoles sobre las imágenes que se veían en los dibujos, ya en el papel, ellos de alguna manera relacionaban esas imágenes con la vía láctea, con el cosmos o el espacio sideral, ¿es esto una regularidad, en el pensamiento moche, podemos relacionar lo que usted observa en la iconografía desde las vasijas, las botellas y los ceramios en su conjunto con el conocimiento imaginario que se ve en la Huaca de la Luna?

JG: Primero para la gente de los andes y también para los moches, no hay algo así como una idea de la vía láctea desligada, sino la vía láctea es algo que tiene un lugar importante en la concepción del espacio que tienen y, quizás con la particularidad que muchas de sus narraciones terminan como diciendo, esta narración cuenta tan 
respecto a las narraciones. Y los testimonios de esto lo pueden ver en la vía láctea, ¡iallí está el resultado de la acción!! En ese sentido, hay una relación directa entre la vía láctea y las narraciones que se cuentan. Segundo, la vía láctea es concebida como una especie de río del cual proviene el agua, que es la base del sustento de la sociedad moche. Y por lo tanto, la vía láctea es sumamente importante en sus concepciones, sobre la organización de la naturaleza, y allí quizás hay una gracia que poca gente ha visto porque desgraciadamente los arqueólogos y también los antropólogos no están muy familiarizados con la naturaleza. Pero los sujetos que investiga la arqueología y la antropología están muy familiarizados con los ciclos de la naturaleza y en la costa norte especialmente en los moche. Es interesante esto que hay en realidad, dos ciclos de humedad y crecimiento de las plantas. El ciclo del valle húmedo, por los ríos que crecen, donde crecen las plantas con la irrigación y el ciclo de las lomas donde las plantas crecen por la humedad de la garúa, de las nubes que entran en realidad en la época seca de los valles. Y entonces, los moche pensaban por qué en la época seca en los valles no se podía ver el cielo. El señor de la vía láctea estaba viviendo en las lomas, porque allí había la humedad, cuando los valles estaban secos la luna, estaban húmedas, las lomas es el lugar donde habita el señor de la vía láctea en la época seca. Ya en la época húmeda está en el cielo. Tiene que organizar que caiga la lluvia, pero en la época seca de los valles, está en las lomas porque allí está la humedad en las lomas. Por desgracia, los antropólogos y los arqueólogos no se han fijado en esos dos ciclos de humedad, y cuál es la relación de los dos ciclos de humedad con las concepciones de la vida que tiene la gente en la costa norte y de la costa en general. Es sumamente interesante, y muestra cómo incluyen en su concepción del mundo, que es muy visible en la iconografía, la naturaleza. Es decir, por ejemplo, la planta que florece en las lomas la utilizan como expresión de esta presencia de la divinidad de la vía láctea en las lomas. Allí por ejemplo están las tilancias, por lo normal las plantas en la época de crecimiento de plantas, se dirigen hacia el cielo, pero las tilancias que son las que florecen en la época húmeda se dirigen en las imágenes moche, hacia el mar. No se dirigen hacia el cielo, es muy fina la percepción de ellos, no es así muy a la gruesa, son muy exactos. Por ejemplo, hay un animal que yo por casualidad he conocido de joven cuando me iba por las playas de la costa norte, que llamaban marucha que vive estrictamente en el espacio entre tierra y mar, allí está metido a la arena y ese animal, la marucha, que para la mayoría de los arqueólogos o los iconógrafos confunden con un ciempiés, es algo así como un animal de transición entre los mundos de contacto entre el mundo de la tierra y el mundo del mar. Allí nuevamente se vuelve una observación muy fina y una integración muy fina de las diversas especies de animales en las concepciones del mundo que expresan en sus imágenes.

PJP: Después de esta gran labor de más de quince años en la iconografía, prioritariamente de la cultura moche, ¿cómo podría relacionar todo este trabajo de investigación con y para el momento actual, coyuntural, por el cual estamos pasando los peruanos?, ¿cómo lo podría manifestar para una sociedad como la nuestra?

JG: Mira, como digo mi intención mirando el pasado y creo que casi todas las intenciones de los historiadores siempre hay que buscarlos en el presente, eso es así. Es decir, los historiadores crean recursos o crean las bases para mantener el presente tal como está o crear recursos para cambiar el presente. Van diez mil años atrás, pero en realidad, apuntan al presente y al futuro, y en ese sentido también mi trabajo tengo que decir, que 
en última instancia, mi intención es apoyar con mi grano de arena a un cambio en la sociedad peruana en la percepción de su pasado, porque pienso que una conciencia clara del pasado, un conocimiento diáfano del pasado, es un punto sumamente importante en la recuperación de la capacidad creativa que los peruanos en el pasado han mostrado, y que ahora está algo apagado y en ese sentido también este libro quiere contribuir a la recuperación de una conciencia fluida de integración del pasado al presente y a la construcción en el futuro.

JP: Muchas gracias Dr. Golte. 